\title{
Calebasse ou gourde
}

M. Gast

\section{OpenEdition}

Journals

Édition électronique

URL : http://journals.openedition.org/encyclopedieberbere/2038

DOI : 10.4000/encyclopedieberbere.2038

ISSN : 2262-7197

\section{Éditeur}

Peeters Publishers

\section{Édition imprimée}

Date de publication : 1 septembre 1992

Pagination : 1710-1713

ISBN : 2-85744-581-4

ISSN : 1015-7344

\section{Référence électronique}

M. Gast, « Calebasse ou gourde », Encyclopédie berbère [En ligne], 11 | 1992, document C10, mis en ligne le 01 avril 2013, consulté le 25 septembre 2020. URL : http://journals.openedition.org/ encyclopedieberbere/2038; DOI : https://doi.org/10.4000/encyclopedieberbere.2038

Ce document a été généré automatiquement le 25 septembre 2020

(c) Tous droits réservés 


\section{Calebasse ou gourde}

\section{Gast}

1 Azenu, tazenut ( $t$ ), gaso (employé au Sahara central par les arabophones) tablawt, tafeqlust (k), takerwayt (moz. et ouargli) ger'a (ar.),tahššit ) (K. calebasse verte), țaȟšešt (k. calebasse sèche).

2 Fruit d'une plante de la famille des Cucurbitacées (Lagenaria vulgaris Seringe) originaire de Chine et probablement aussi d'Abyssinie où elle a été signalée à l'état spontané. Ibn Batouta voyageant au Niger signalait vers 1350 que les femmes noires utilisaient couramment de grosses calebasses posées sur leurs têtes pour transporter leurs provisions. La plante qui fournit la calebasse affectionne les lieux bien ensoleillés, un sol humide et des supports (arbres, épineux) pour développer ses tiges qui grimpent comme des lianes auxquelles sont suspendus les fruits, ainsi à l'abri de la pourriture du sol et des petits rongeurs. Elle pousse dans presque toutes les régions en Afrique du Nord et au Sahara. Elle est le plus souvent cultivée pour ses fruits qui, arrivés à maturité et séchés, sont vidés de leurs graines et des membranes de cellulose qui supportent celles-ci, pour devenir des récipients utiles à toutes sortes d'usages. D'autant plus que les formes de ces fruits sont extrêmement diverses: oblongues, sphériques, incurvées, mais le plus souvent en forme de grosse poire. Les Touaregs distinguent au Sahara central deux plantes qui fournissent des calebasses. Tetakelt produit une courge comestible quand celle-ci est cueillie encore verte et tendre; on l'utilise comme légume dans les ragoûts, sauces et bouillons ; on peut aussi la couper en morceaux et la faire dessécher comme le potiron ou la pastèque fourragère. Si on laisse cette gourde mûrir et se dessécher naturellement sur pied, elle peut servir de bouteille à contenir de l'eau, du lait, du beurre, du miel, ou de vase à boire si on la coupe en deux hémisphères, de caisse pour les violons monocordes (imzad ${ }^{*}$ ), de louche quand il s'agit d'un petit fruit coupé verticalement (la partie étroite servant de manche et la partie renflée coupée en deux, utilisée en louche). l'ateklas est apparemment la même plante, mais dont le fruit n'est pas comestible. Cette plante existe aussi en Ahaggar mais elle est beaucoup plus fréquente dans les pays au sud du Sahara (voir Foucauld, 1952, IV : 1890). Le fruit de l'ateklas est uniquement transformé en objet domestique. En pays touareg comme en Afrique au sud du Sahara, les objets en écorce de calebasse sont le 
plus souvent ornés de décors géométriques pyrogravés, sculptés au couteau ou peints, d'un bel effet.

Calebasse à décor pyrogravé (Niger). Photo G. Camps.

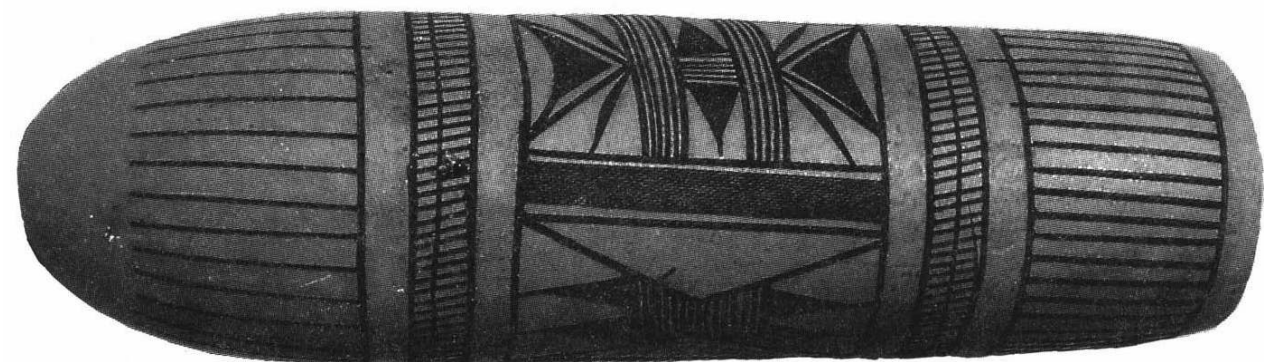

Calebasse à décor incisé (Ahaggar). Photo M. Bovis.

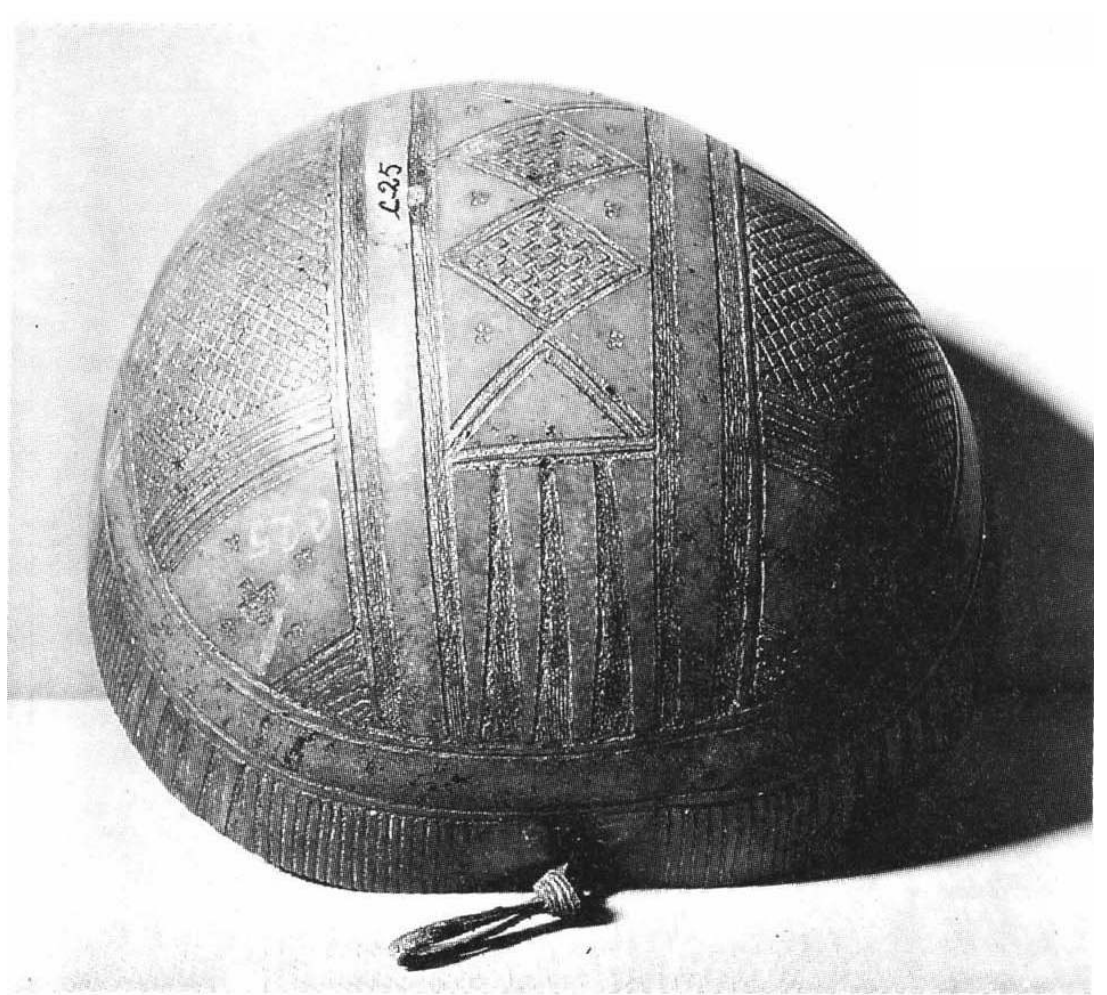


Gourde avec col en vannerie (Tchad). Photo G. Camps.

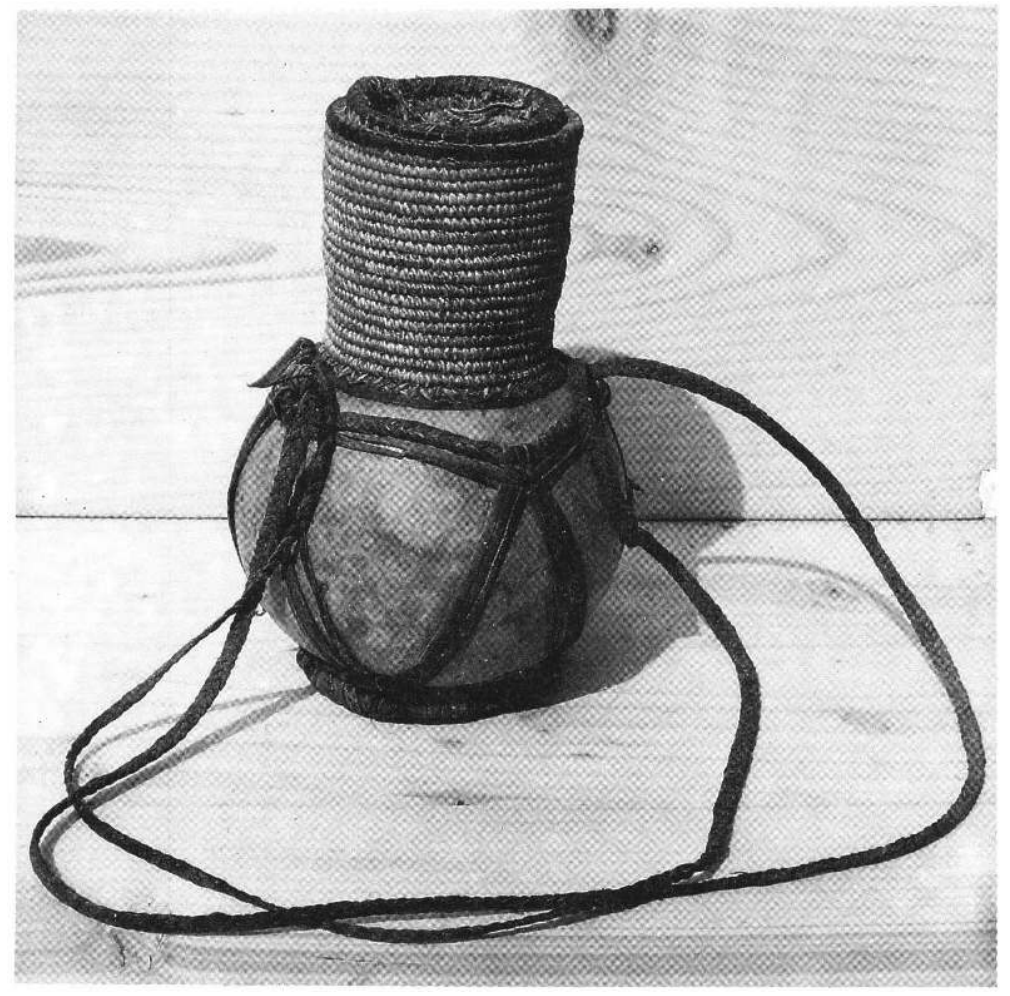

Baratte-calebasse dans un campement touareg. Noter la réparation à l'aide d'une pièce de cuir. Photo M. Gast.

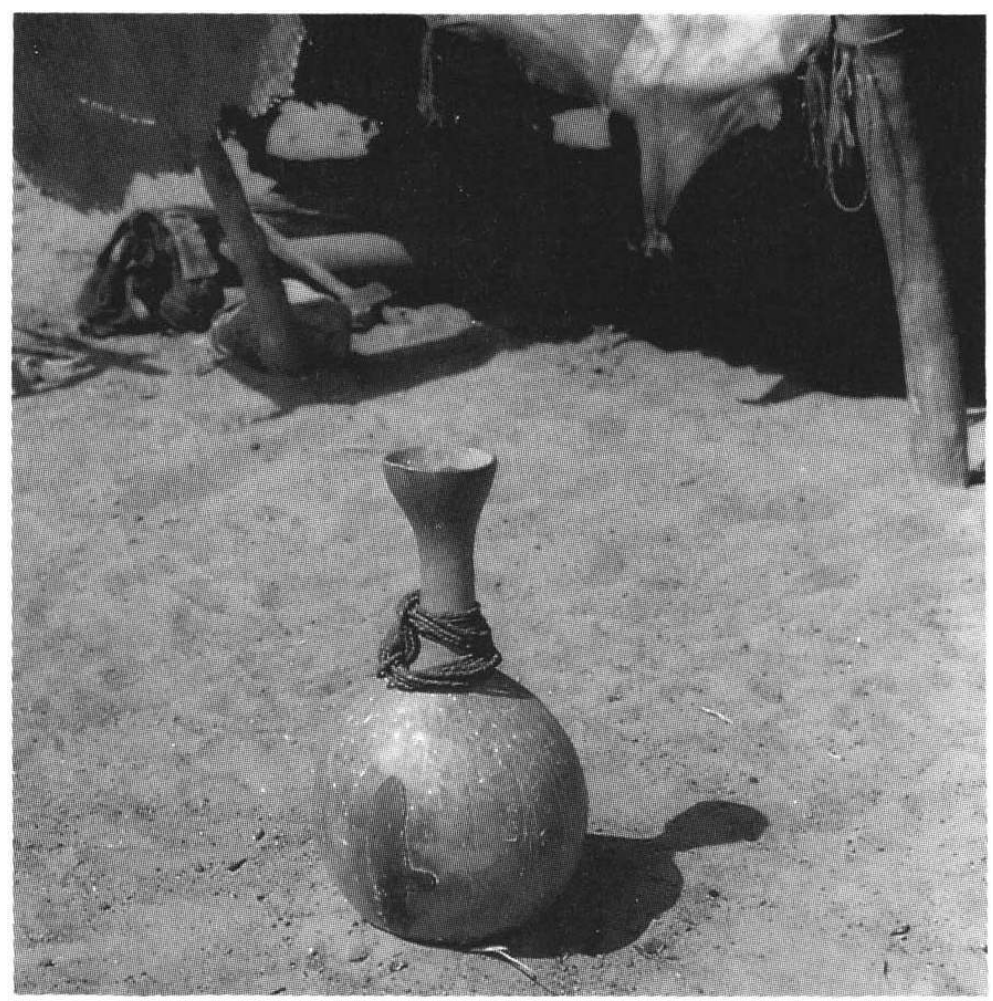

3 Quand Lagenaria vulgaris pousse sous un climat et sur un sol favorable, elle peut fournir des calebasses énormes, atteignant jusqu'à 70 litres de volume, et qui peuvent servir de 
réserve à grains dans les maisons. Cependant, tous ces récipients doivent être manipulés avec précaution car les parois, quelle que soit leur épaisseur, résistent peu aux chocs. Les écorces de calebasses brisées sont parfois recousues avec art par les artisans, sinon encore utilisées telles quelles comme écuelles pour nourrir les animaux ou comme raclettes pour décrotter les bébés en pays touareg.

4 Les calebasses de petite taille sont facilement transformées en bouteilles. Dans les régions sud-sahariennes, la partie supérieure de la calebasse peut recevoir un col en vannerie cousu à la paroi et la panse peut être complétée par un pied en même matière. En Afrique du Nord (Kabylie, Aurès, Atlas marocain) la calebasse sert très souvent de baratte (de 3 à 51 de capacité), l'ouverture à la partie supérieure étant fermée par un gros bouchon de liège ou de bois. Les calebasses sont aussi employées dans des rites magiques « à l'exclusion de tout autre vase, en raison du caractère sacré qui s'attache à elles comme leur nom l'indique ([lebni er-reppwi] la "Maison de Dieu"), et c'est pourquoi une petite gourde est souvent suspendue au-dessus du berceau» (G. LaoustChantréaux, 1990 : 54).

Les petites calebasses en forme de gourde possèdent un étranglement qui facilite la préhension ou la suspension. Elles sont à l'origine de certaines formes de vases à boire (tabuqalt) qui, au-dessus de leur panse sphérique conservent un col renflé caractéristique.

\section{BIBLIOGRAPHIE}

CHEVALLIER A., Ressources végétales du Sahara et des confins nord et sud, Paris, Muséum d'Histoire Naturelle, 1932 (pp. 120-121).

FOUCAULD P. Ch. de, Dictionnaire touareg français, 4 vol., Paris, Imprimerie Nationale, 1952.

GAST M., Alimentation des populations de l'Ahaggar, Mémoires du CRAPE VIII (Alger), Paris, A.M.G., 1968 (pp. 376-380-384).

HEISER C.B. jr., The gourd book, University Oklahoma Press, Norman, OK, 1979.

LAOUST-CHANTREAUX G., Kabylie côté femme. La vie féminine à Aït-Hichem, 1937-1939, Aix-en-Provence, Édisud, 1990, 304 p.

\section{INDEX}

Mots-clés : Artisanat, Ethnographie, Niger, Sahara, Technologie 